\title{
A Conceptual Framework on IT Governance Impact on Organizational Performance: A Dynamic Capability Perspective
}

\author{
Saida Harguem \\ Assistant Professor, \\ Faculty of Management, \\ Canadian University Dubai, \\ Dubai, United Arab Emirates
}

DOI: https://doi.org/10.36941/ajis-2021-0o12

Abstract

Recent years have seen substantial growth in Information Technology Governance (ITG) research. However, the influence of ITG on organizational performance has been less covered and very little theorized. To address this gap, the purpose of this paper is to build a conceptual framework to provide a better understanding of ITG contribution to organizational performance. Based on an extensive literature review on ITG and guided by the dynamic capabilities perspective, the proposed conceptual framework analyses the ITG - Organizational Performance relationship through the lenses of the dynamic capability perspective and generate a set of five research propositions. The proposed framework suggests that the effectiveness of ITG mechanisms (structures, processes, and relational mechanisms), contribute to the development of a dynamic ITG competence which has an impact on the development of IT management capabilities and their evolution. Moreover, the proposed conceptual framework suggests that ITG is more likely to lead to better organizational performance when IT management capabilities are developed in line with business strategy.

Keywords: IT Governance, Information Technology, IT management sophistication, strategic alignment, organizational performance, dynamic capabilities perspective

\section{Introduction}

Information Technologies (IT) are revolutionizing the business world. In addition to providing support for daily operations, they are today an integral part of business processes within and across organizational boundaries. Despite the pervasive use of IT in all business spheres, many organizations still fail to demonstrate concrete, measurable business value from IT (IT Governance Institute, 2008). Business leaders and IT executives are developing major concerns about the alignment of IT with business needs and the impact of IT on productivity and costs reduction (Luftman \& Zadeh, 2011). Thus, it has been argued that effective IT Governance (ITG) could increase IT business value and achieve business goals (Juiz \& Toomey, 2015).

For instance, Weill and Ross (2004) found that successful companies in terms of ITG tend to experience a $20 \%$ increase in profits, higher returns on equity and growth in market capitalization than other companies pursuing similar strategies. Although, it has been observed that superior ITG performance may be correlated to higher financial performance, few studies have empirically addressed 
the impact of ITG on organizational performance (Boritz \& Lim 2007; Bradley et al., 2012; Jewer \& McKay, 2012; Lazic, Groth, Schillinger, \& Heinzl, 2011; Liang, 2011), and much less on how ITG could contribute to improving organizational performance (Lazic et al., 2011). To address this gap, the purpose of this theoretical study is to develop a conceptual framework that demystifies the relationship between ITG and organizational performance.

The remainder of this article is organized in a series of interrelated sections. In the next section, we review salient literature on ITG and related concepts. We then present the principles of dynamic capabilities perspective, used in this paper to guide the development of a comprehensive conceptual framework on ITG impact on organizational performance and demonstrate five propositions associated with it. Finally, we discuss the contributions and limitations of the conceptual framework and propose avenues of future research in this domain.

\section{Literature Review: IT Governance}

ITG is often presented as an integral part of corporate governance (Weill \& Ross, 2004). It consists of the leadership, organizational structures, and processes that ensure that the organization's IT sustains and extends the organization's strategies and objectives (IT Governance Institute, 2003). More specifically, ITG occurs through the specification of decision rights and accountabilities framework designed to encourage desirable IT-related behavior within an organization (Weill \& Ross, 2004).

Review of past research shows that ITG research has mainly focused on four main streams: the design of IT decision-making structures, ITG implementation, ITG performance, and ITG outcomes.

\subsection{Design of IT Decision-Making Structures}

The first stream of ITG research deals with the decision-making structures adopted in the design of IT organizations. An extensive body of past research was dedicated to this area (for a detailed review on this topic, see Brown and Grant (2005)). More specifically, research in this stream focused on the description of decision-making structures adopted by individual IT organizations through the specification of the distribution of roles and responsibilities for decision-making on various organizational IT activities. Early research dealt with three primary ITG modes, namely centralized, decentralized, and federal/hybrid governance modes (Ein-Dor \& Segev, 1982; Olson \& Chervany, 1980; Sambamurthy \& Zmud, 1999). In these IT organizational structures, decision-making authority is placed respectively within a central IT unit, business units or a combination of both. Thereafter, Weill and Ross (2004) expanded the traditional ITG forms and proposed six governance classifications to IT organizations based on the ideal of political archetypes. These archetypes include: business monarchy (IT decisions are made by $\mathrm{CxOs}$ ), IT monarchy (Corporate IT professionals make the IT decision), feudal system (IT decision by autonomous business units), federal system (Hybrid decision making), IT duopoly system (IT executives and one business group), and anarchy (each small group makes decisions). Moreover, in past research we noticed a consensus among researchers on the fact that a universal best ITG structure does not exist. Rather the best ITG solution for a given organization is contingent on a variety of factors (Brown \& Magill, 1994; Sambamurthy \& Zmud, 1999; Tavakolian, 1989), including corporate governance, business strategy, and organizational size, among others.

\subsection{IT Governance Implementation}

The second stream of ITG research focusing on the deployment of ITG in organizations can be classified as either normative or descriptive. The normative studies (e.g., Dahlberg \& Kivijarvi, 2006; De Souza Bermejo \& al., 2014; Fink, 2008; Goosen \& Rudman, 2013; IT Governance Institute, 2005; Subsermsri \& al., 2015) offer frameworks, methods, or guidelines to foster the effective implementation of ITG in organizations. This research also addresses adherence to internationally recognized standards and best practices (such as COBIT, ITIL, ISO17799: 2000, AS8015) intended to facilitate effective organizational 
deployment of ITG. For example, as a structured approach to ITG, the COBIT method (Control Objectives for Information and related Technology) provides managers, auditors, and IT users with performance indicators to assist the supervision of IT implementation within the organization (IT Governance Institute, 2005). Descriptive studies (e.g., Bhattacharjya, 2007; De Haes, Gemke, Thorp, \& Van Grembergen, 2011; De Haes \& Van Grembergen, 2009; Grüttner, 2010; Weill \& Ross, 2004; Vaia \& Carmel, 2013; Van Saull, \& De Haes, 2003; Williams \& Karahanna, 2013) illustrate the ways in which organizations implement a framework for ITG. These studies have shown that ITG is often deployed using a combination of various practices, namely organizational structures, processes, and relational mechanisms (Peterson, 2004; Van Grembergen, De Haes, \& Guldentops, 2004; Weill \& Ross, 2004). ITG structures include the establishment of organizational units and the definition of formal positions and roles responsible for IT decisions making processes that enable horizontal contact between the business and IT management functions within the organization (De Haes \& Van Grembergen, 20o8; Peterson, 2004). These structures (e.g., IT steering committee, IT strategy committee, IT expertise at the board level) include decision makers from various levels in the organization: corporate executives, IT management personnel, and business managers (Peterson, 2004; Weill \& Ross, 2004). ITG processes refer to the formalization and institutionalization of IT strategic decision-making and IT monitoring procedures (e.g., IT strategic planning, system performance measurement [IT Balanced Scorecard, COBIT, ITIL]) (De Haes and Van Grembergen, 2008; Peterson, 2004) to ensure that daily activities are consistent with existing long-term policies and provide feedback necessary to guide decisions (Peterson, 2004; Van Grembergen et al., 2004; Weill \& Ross, 2004). Finally, relational mechanisms refer to the active participation of and collaborative relationship among corporate executives, IT management personnel, and business management personnel in relation to ITG (Peterson, 2004; De Haes \& Van Grembergen, 2008). ITG relational mechanisms (e.g., co-rotation positions, co-location and training) are often essential for promoting alignment between IT strategy and business needs (Bhattacharjya \& Chang, 2007; Callahan \& Keyes, 2004; Van Grembergen et al, 2004).

\subsection{IT Governance Performance}

The Third stream of research which focuses on the performance of ITG, has been approached in two ways: through the evaluation of overall ITG performance (Barbosa \& al., 2014; Bradley \& Pratt, 2011; Coleman \& Chatfield, 2011; Lahdelma \& Dahlberg, 2007, Lee et al, 2009; Simonsson, Johnson \& Ekstedt, 2010; Tugas, 2010, Weill \& Ross, 2004) and the assessment of individual ITG mechanisms adopted by the organization (Ali \& Green, 2005, 2007, 2012; Bradley et al., 2012; De Haes \& Van Grembergen, 2008; Ferguson, Green, Vaswani, \& Wu, 2013; Heindrickson \& Carlos, 2014).

\subsubsection{Evaluation of the overall performance of IT Governance}

Weill and Ross (2004) were the first to propose an evaluation of the overall performance level of ITG in organizations. They proposed an assessment tool that is based on a comparative analysis of the organization's ITG outcomes relative to the established goals. Other researchers have subsequently expanded the measurement of ITG performance by gauging its maturity level using COBIT performance indicators (Cobo \& al., 2014; Coleman, 2011; Simonsson et al., 2010; Tugas, 2010; Lee, Lee, Park, and Jeong, 2008). While other researchers (e.g. Dahlberg \& Kivijarvi, 20o6; Dahlberg \& Lahdelma, 2007) have based their measurement on ITG objectives (i.e. strategic alignment, value creation, risk management, management of IT resources and IT management performance) as an evaluation criteria to assess ITG maturity.

\subsubsection{Assessment of IT Governance mechanisms}

De Haes and Van Grembergen (2008) have examined the performance of ITG mechanisms. Specifically, they have evaluated the performance of these mechanisms according to industry experts by assessing 
their maturity, ease of implementation, and perceived effectiveness. Other researchers (Bradley \& Pratt, 2011; Bradley et al., 2012) have assessed ITG by measuring the degree to which an organization uses ITG mechanisms. Finally, another contingent of researchers (Ali \& Green, 2005, 2007, 2012; Ferguson et al., 2013; Heindrickson \& Carlos, 2014, Lunardi \& al. 2017) measured the extent to which ITG in organizations is effective. To perform this evaluation, these scholars have empirically examined the influence of individual ITG mechanisms on the overall effectiveness of ITG.

\subsection{IT Governance Outcomes}

Finally, the fourth stream of research on ITG explores the influence of ITG mechanisms on the alignment between IT and business strategy. In addition, this stream of research also addresses the influence of ITG on organizational performance.

\subsubsection{IT Governance and IT/Business alignment}

The first objective of ITG is to ensure closer alignment between the organization's IT and business strategies (IT Governance Institute, 2003). In recent years, researchers have studied this assumed relationship by exploring how the implementation of ITG can contribute to a better strategic alignment of IT with business needs (Beimborn, 2009; De Haes \& Van Grembergen, 2009; Kuruzovich et al, 2012; Preston \& Karahanna, 2009; Schlosser \& Wagner, 2011). Studies on this issue have specially examined the influence of ITG mechanisms (structures, processes, and relational mechanisms) on the strategic alignment of IT in the organization. For instance, De Haes and Van Grembergen (2009) found that organizations that use a combination of more mature ITG mechanisms were likely to achieve greater strategic alignment. Subsequent studies have quantitatively examined the correlation between the use of one or more ITG mechanisms and the achievement of IT strategic alignment in organizations. For example, Beimborn et al. (2009) illustrated that the support of senior management as a structural governance mechanism yields greater IT strategic alignment. Similarly, Preston and Karahanna (2009) explored the influence of the degree to which the Chief Information Officer (CIO) participates in the Top Management Team (TMT) and the hierarchical status of the CIO (i.e., whether the CIO reports directly to the Chief Executive Officer (CEO)) on strategic alignment. The specific relationship between the $\mathrm{CIO}$ and the Chief Financial Officer (CFO) was also considered as a critical pairing, which impacts both individual effectiveness and strategic alignment (Schobel \& Denford, 2012). As denoted by the authors, these mechanisms promote interaction, knowledge exchange, and knowledge integration between the CIO and the TMT, thereby contributing to the development of a shared understanding about the role of IT within the organization ( which represent the social dimension of IT strategic alignment) (Preston \& Karahanna, 2009). In another study, Kuruzovich and his colleagues (2012) examined the role of the board of directors in driving IT alignment. They found that (a) the direct involvement of the board of directors in managing IT, (b) CIO communications with the board, (c) strategic consideration of IT investments, and (d) the amount and usefulness of the information provided to the board of directors regarding IT promote IT alignment in organizations (Kuruzovich et al., 2012). Other researchers have investigated the use of IT steering committees as structural ITG mechanism (De Haes \& Van Grembergen, 2009; IT Governance Institute, 2003; Van Grembergen et al., 2004). In this context, IT steering committees are found to significantly contribute to the strategic alignment of IT with business strategies (Schlosser \& Wagner, 2011).

\subsubsection{IT Governance and Organizational Performance}

Researchers have also examined the influence of ITG on organizational performance (Boritz \& Lim, 2007; Bradley et al., 2012; Jewer \& McKay, 2012; Lazic et al, 2011; Liang et al., 2011). Boritz and Lim (2007), for example, showed that organizational use of high-level ITG mechanisms (e.g., IT strategy committee, $\mathrm{CIO}$ position) generate improved financial performance. Similarly, Jewer and McKay (2012) reported 
that board involvement in ITG positively moderates the relationship between ITG implementation and organizational performance. Moreover, High levels of board-level ITG increases organizational performance (Turel \& Bart, 2014). Liang et al. (2011) stated that ITG performance is related to better strategic alignment of IT, which in turn improves organizational performance. Related to this, a recent study by Bradley et al. (2012) showed that the quality of ITG mechanisms positively contributes to organizational performance among public and private hospitals by improving relationships with customers, market responsiveness, and operational efficiency.

Taken together, researchers have shown that there exists a positive relationship between the quality of ITG and organizational performance. Although they have done much to reveal the positive correlation between ITG and observed improvement in organizational performance, there is still a research gap on how ITG may improve organizational performance. In past ITG literature, only Lazic and his co-authors (2011) have sought to explain how organizational performance is positively affected by ITG. They explained that ITG is positively related to business performance through common use of IT resources, IT processes, and business processes throughout the organization's various business units.

Despite the various foci of the research described above, researchers appear to agree that ITG occurs through an organizational structure that specifies roles and responsibilities for IT decisionmaking. The overall structure operates through mechanisms or ITG practices. These take the form of structures (committees, liaison roles), processes (methodologies and best practices for IT strategic management, IT monitoring and control), and relational mechanisms (communication and collaboration among different IT and business stakeholders). The organization can leverage a wide range of mechanisms to implement ITG (De Haes \& Van Grembergen, 2009, Peterson, 2005). Through a combination of mechanisms, ITG ensures the planning, organization, and control of IT-related activities (Prasad, Heales, \& Green, 2010) in order to achieve better strategic alignment of IT capabilities with business needs (De Haes \& Van Grembergen, 2009) and attains superior performance of the organization as whole (Prasad et al., 2010).

Based on the above literature review, we note that there has been little research that investigates the relationship between ITG and organizational performance, even less has attempted to explain how ITG influences organizational performance. In addition, previous research has demonstrated that to maximize IT value, the mere implementation of ITG is not sufficient. It is important that the implemented practices are mature enough to generate the expected value for the organization (De Haes, Van Grembergen, 2009). Indeed, an organization must constantly question the effectiveness of the implemented ITG mechanisms and revise them in an active ITG design process geared towards promoting the enterprise's objectives and performance goals (Weill \& Ross, 2004). As stated by Weill and Ross (2004), it is important not only to actively design the overall ITG, but also to review individual mechanisms regularly as a perquisite to mature IT management capabilities and maximize their contributions to the business. Therefore, there seems to be a close relationship between ITG performance and the effectiveness of IT management capabilities of the organization. For instance, Karimi, Bhattacherjee, Gupta, and Somers (2000) have demonstrated that the effective use of IT steering committees (a structural ITG mechanism) has a positive impact on IT management sophistication. As such, we may think that the level of IT management sophistication could be an indicator of the performance of ITG achieved in the organizations as well as an enabler for strategic alignment and organizational performance.

\section{IT Management Sophistication as a Measure of IT Governance Effectiveness}

Past research on IT management sophistication (also called IT maturity) suggests the use of IT management practices as benchmark variables for measuring the progression of organizations toward IT management sophistication (Gupta, Karimi \& Somers, 1997; Huang, 2009; Karimi et al., 2000; Karimi, Gupta, \& Somers, 1996; Karimi, Somers, \& Gupta, 2001; Kim, Shin, Kim, \& Lee, 2011). In particular, previous studies suggested the use of practices including IT planning, IT control, IT investment decision-making (Kim et al. 2011), IT organization, IT coordination (Kim, Shin, Kim, \& Lee, 2011), and 
IT integration (Karimi et al., 1996). It is argued that higher level of IT management sophistication would imply a significant formalization of the different IT management practices (Karimi et al., 200o).

As such, IT management sophistication characterizes organizations' evolution of their IT managerial practices toward greater formalization in line with business needs and context. This in turn would suggest that IT function in an organization with higher levels of IT management sophistication would have evolved from a simple data-processing orientation into a strategic IT orientation (Gupta et al., 1997). We argue that it is through the deployment of effective ITG mechanisms that the organization's IT management capabilities will evolve toward greater sophistication. This in turn will increase the IT function contribution to organization's goals and objectives (IT Governance Institute, 2003) by enabling strategic alignment and consequently promoting improvement in organizational performance.

Past research on ITG focused greatly on coordination theory to describe ITG deployment strategies in organizations. Although, the use of coordination theory has contributed a lot to the growing body of research on ITG, we think, that it lacks to highlight the adaptive capacity of ITG to organizational environment. As an attempt to address this gap, we have focused on the dynamic capabilities' perspective as a way of theorizing about ITG and its impact on organizational performance.

\section{Theoretical Background: From Coordination Theory to Dynamic Capabilities Perspective}

For decades, coordination theory has received attention from researchers in different disciplines. This theory has been used to analyze the design of complex processes. Thus, coordination theory has largely contributed to manage dependencies in several settings by providing a wide range of coordination mechanisms, including the standardization of processes, rules, and procedures (Thompson, 1967; Lawrence \& Lorsch, 1967), mutual adjustment, direct contacts, meetings (Thompson, 1967; Lawrence \& Lorsch, 1967), integrators and liaison roles (Lawrence \& Lorsch, 1967, Galbraith, 1973), project teams, committees (Lawrence \& Lorsch, 1967), objectives setting, standardization of results (Galbraith, 1973; Mintzberg, 1979), the matrix structure (Galbraith, 1973), and the standardization of skills through training (Mintzberg, 1979).

Coordination theory is based on two principal claims: 1) dependencies and the mechanisms to manage them can be found in a variety of organizational settings (i.e. generality of coordination mechanisms); and 2) there are often several coordination mechanisms that can be used to manage a dependency (Crowston \& Osborn, 1998).

Past research on ITG as depicted in the previous section, are heavily influenced by coordination theory principles. In fact, these principles inspired the analysis of ITG deployment strategies in organizations (e.g. Agarwal \& Sambamurthy, 2002; Brown, 1997, 1999; Brown \& Ross, 2003; Peterson, 2000; Peterson, 2004; Weill \& Ross, 2004; De Haes \& Van Grembergen, 2008, 2009). Moreover, past research has largely sought to describe and explain how organizations employ formal and informal coordination mechanisms to allow ITG stakeholders to coordinate their efforts and better manage interdependencies in the organization's IT activities. Thus, it was argued that ITG can be deployed using a mixture of structures, processes and relational mechanisms (Peterson, 2004; Weill \& Ross, 2004; De Haes \& Van Grembergen, 2008, 2009). Moreover, Past research has come up with specific ITG mechanisms as a general baseline in the deployment of ITG in organizations (Weill \& Ross, 2004; De Haes \& Van Grembergen, 20o8). Together, the coordination theory approach has significantly contributed to ITG research by setting a theoretical framework that guides the analysis of ITG deployment in organizations. However, this theoretical framework lacks the consideration of the dynamic nature of the organizational environment, as it promotes the generality of coordination mechanisms under different organizational context. We believe that the dynamic capabilities perspective can be considered as an alternative theoretical framework to analyse ITG dynamics and its contribution to organizational performance. 


\section{1 \\ Applying the Dynamic Capabilities Perspective to IT Governance Context}

The notion of dynamic capabilities is typically presented as complementary theory to the resourcebased view (RBV) of the firm (Priem \& Butler, 2001; Wang \& Ahmed, 2007). It strengthens arguments related to the RBV and overcome its static perspective by addressing the changing nature of resources and expertise possessed by organizations in light of a highly dynamic business environment (Wang \& Ahmed, 2007). As defined by Teece et al. (1997) “dynamic capabilities refer to the firm's ability to integrate, build and reconfigure internal and external competences to address rapidly changing environments". Organizations create their dynamic capabilities and develop them over time through a combination of processes and coping mechanisms, absorption, and innovation (Wang \& Ahmed, 2007). These capabilities extend and modify the resource and capabilities base of an organization (Ambrosini, Bowman, \& Collier, 2009). According to Wang \& Ahmed (2007), dynamic capabilities are embedded in processes and are firm specific. Moreover, they are perceived as conductive to long-term firm performance (Pavlou \& El Sawy, 2006; Teece, 2007; Wang \& Ahmed, 2007). They also present certain commonalities across organizations that are identifiable and measurable (Eisenhardt \& Martin, 200o). Therefore, recent research focused on clarifying the foundations of dynamic capabilities, usually within a conceptual discussion of firm resources and capabilities in a hierarchical order (Ambrosini, Bowman, \& Collier, 2009; Pavlou \& El Sawy, 2011; Teece, 2007; Wang \& Ahmed, 2007). For instance, Teece (2007) advances that dynamic capabilities can be disaggregated into sensing, seizing and transformational activities. Wang and Ahmed (2007) recognize that adaptive capability, absorptive capability and innovative capability are the most important component factors of dynamic capabilities. Pavlou and El Sawy (2011) suggest sensing the environment, learning, coordinating and integrating capabilities as micro-foundations of dynamic capabilities. Finally, building on prior research, Ambrosini et al. (2009) extent the concept of dynamic capabilities and suggest that there are three levels of dynamic capabilities, namely incremental, renewing and regenerative dynamic capabilities.

Throughout the different conceptualizations depicted in the literature, dynamic capabilities actually consist of "identifiable and specific routines that often have been the subject of extensive empirical research in their own right" (Eisenhardt \& Martin, 2000, p. 1107). In sum, dynamic capabilities govern the rate of change of operational capabilities to keep them valuable in response to environmental change (Collis, 1994).

In Information Systems (IS) research, the dynamic capabilities perspective was essentially used to explain the changing nature of organizational capabilities during the process of IT strategic planning (Duhan, 2007) and to analyze the dynamics of the IT strategic alignment process (Baker et al, 2011; Chen et al, 2008; Pelletier, 2012) as well as understanding organizational designs in IT-related capabilities development (Prasad, Green, \& Heales, 2013).

Using similar argumentation as for "dynamic capabilities", we believe that a rationale could be built up for ITG and its impact on organizational performance. In the following section, we propose an integrated framework for understanding ITG impact on organizational performance in light of the dynamic capabilities' perspective. Thus, we reckon that ITG is a dynamic capability competence that impacts the organization's IT management capabilities development and evolution (i.e. IT management sophistication) as directed by the business strategy, resulting on better strategic alignment leading ultimately to better organizational performance (when IT management capabilities are developed in line with the organization's strategic choices).

\section{IT Governance Impact on Organizational Performance: Conceptual Framework and Propositions}

As said earlier, the conceptual framework presented in Figure 1 uses dynamic capabilities perspective to provide a more comprehensive understanding of the influence of ITG on organizational performance. 


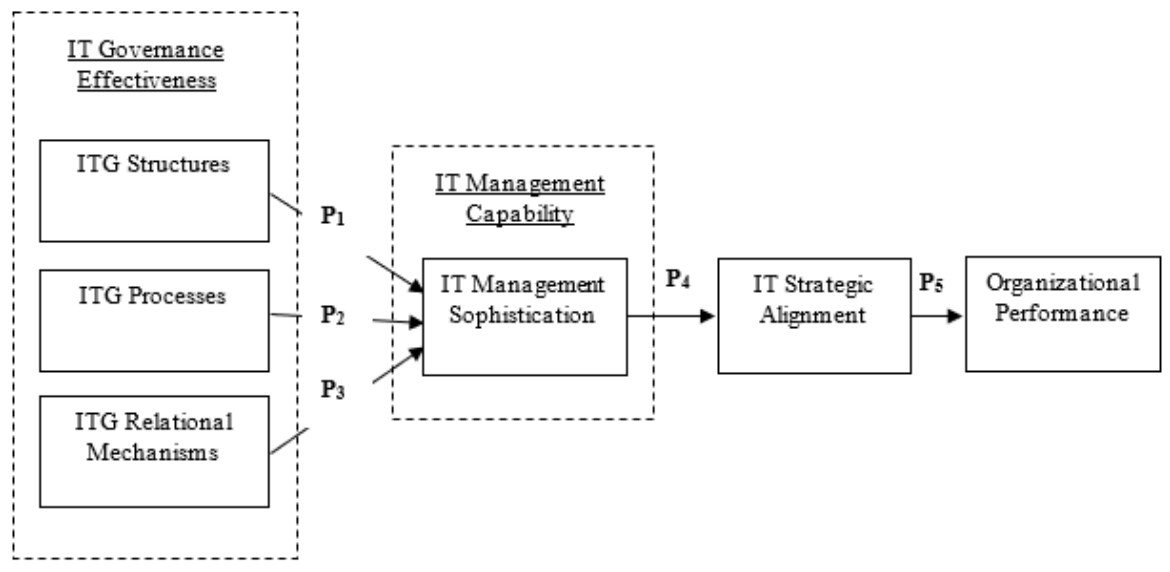

Figure 1: Conceptual Framework

Through this framework (see Figure 1), we suggest that the relationship between ITG and organizational performance is more complex than a simple and direct effect. Instead, the proposed conceptual framework incorporates IT management sophistication and strategic alignment as mediators of the ITG and organizational performance relationship.

The rationale behind the proposed model is illustrated through the following research propositions.

\subsection{IT Governance Mechanisms and IT Management Sophistication}

As mentioned in past research, the essence of dynamic capabilities is an organization's constant pursuit of the reconfiguration, integration and re-creation of its resources, capabilities and most importantly upgrade and reconstruct its core capabilities in response to the environmental change to attain and sustain competitive advantage (Wang \& Ahmed, 2007).

Drawing on dynamic capabilities perspective, we reckon that ITG is a dynamic capability competence that focus on the renewal, reconfiguration and re-creation of IT resources, capabilities and core IT capabilities (e.g. IT management capabilities) to address the (internal and external) environmental change. In ITG context, environmental change can be caused by a combination of several factors including regulatory change, technological innovation or the changing competitive nature of the industry and the organization's need of growing into new business models that it generates (IT Governance Institute, 2008).

As a result, the organization needs to upgrade and recreate its core IT capabilities including its IT management capabilities to be able to respond to internal and external environmental change. According to Wang and Ahmed (2007), capability development and evolution is an outcome of dynamic capabilities. Thus, dynamic capabilities govern the rate of change of capabilities (Collis, 1994). Drawing on this, we posit that the development and evolution of IT management capabilities (i.e. IT management sophistication) is an outcome of ITG (as a dynamic capability competence). As such, ITG has an impact on the development of IT management capabilities and their evolution.

The literature on dynamic capabilities has identified a range of processes and routines that can be recognized as providing certain micro-foundations for dynamic capabilities. For instance, Eisenhardt and Martin (200o) identify cross-functional R\&D teams, new product development routines, quality control routines, and technology transfer and/or knowledge transfer routines, and certain performance measurement systems as important elements (micro-foundations) of dynamic capabilities. To make a parallel with these findings, ITG can be deployed using a mixture of ITG 
practices, namely structures, processes and relational mechanisms (De Haes \& Van Grembergen, 20o8; Peterson, 2004; Weill \& Ross, 2004). As such, we consider ITG mechanisms as micro-foundations of ITG dynamic competence that underpin an organization's ability to reconfigure, renew and recreate its IT resources, capabilities and core IT capabilities and most important influence IT management capabilities development and evolution (i.e. IT management sophistication).

\subsubsection{IT Governance Structural Mechanisms and IT Management Sophistication}

Structural mechanisms, such as IT steering committees, IT strategy committees, and involvement of senior management in IT affect IT management sophistication by providing the organizational structures to support the development and evolution of the different IT management capabilities (e.g. IT planning, IT investment decision-making, IT coordination, etc.) in line with strategic goals and objectives (IT Governance Institute, 2003; Karimi, Bhattacherjee, Gupta, \& Somers, 2000; Peterson, 2004; Prasad, Heales, \& Green, 2010). For instance, Karimi et al. (2000) showed that companies using IT steering committees tend to have higher degrees of IT management sophistication than those that do not. Moreover, the IT Governance Institute has established the importance of such committees in developing, implementing, and conducting effective ITG (IT Governance Institute, 2003). Indeed, many organizations carry out their ITG deployment trough such committees in order to drive IT strategy development and implementation. The establishment of well-balanced committees with the representation of key members that includes business as well as IT representatives enhances the effectiveness of such committees (De Haes \& Van Grembergen, 2008). Indeed, Successful ITG structures requires communication amongst all parties based on constructive relationship to foster understanding organization's IT-related competencies and forge ways to increment them (Prasad et al., 2013). As such, we argue that structural mechanisms as part of ITG dynamic competence contribute to the organization's ability to upgrade and recreate its IT management capabilities as important IT core capabilities. Based on these arguments, we offer the following proposition:

P1: Effective IT governance structures have a positive impact on IT management sophistication.

\subsubsection{IT Governance Processes and IT Management Sophistication}

Effective ITG is also deployed through the institutionalization and formalization of strategic IT decision-making and IT monitoring procedures (De Haes \& Van Grembergen, 2009). For example, strategic information systems planning is one of the most effective ITG processes used by companies to define and update the IT strategy (De Haes \& Van Grembergen, 2009). This mechanism, if effectively used, contributes to the formulation of an IT strategy that meets business needs (Peterson, 2004). This would suggest that strategic information systems planning mechanism as part of ITG dynamic competence will influence IT management sophistication through organization's IT planning capability development and evolution in line with strategic goals and objectives. IT performance measurement system (e.g., IT balanced scorecard) is another example of governance process that is widely recognized as useful process in terms of management control of IT success (Van Grembergen, 2000; Van Grembergen, Saull, \& De Haes, 2003) . In addition, this system uses to be one of the most effective processes of ITG that aids organizations to achieve IT and business alignment (IT Governance Institute, 2003). For instance, IT balanced scorecards are used to help to understand how the contribution of IT towards the business will be realized (Van Grembergen et al., 2003) by focusing on tangible as well as intangible elements (i.e. financial, customer, internal process and learning perspectives) (IT Governance Institute, 2003). This would suggest contributor role of performance measurement systems in fostering sensing and learning capabilities of ITG dynamic competence. Past research also noticed that the effective use of performance measurement systems such as an IT balanced scorecard contribute in supporting IT management practices monitoring and adjustment in line with business needs (Chang \& King, 2003; Decoene \& Bruggeman, 2006; Hu \& Huang, 2006). It helps also to foster consensus among key stakeholders about IT's strategic goals, to communicate about 
IT's performance, risk and capabilities as well as IT's effectiveness and added value (IT Governance Institute, 2003, 2008) thus promoting coordinating capability as a dynamic component factor of ITG. Therefore, we propose that:

P2: Effective IT governance processes have a positive impact on IT management sophistication.

\subsubsection{IT Governance Relational Mechanisms and IT Management Sophistication}

The deployment of an effective ITG framework can be facilitated by multiple relational mechanisms (e.g., co-rotation positions, co-location, training, Knowledge management on ITG). We argue that relational mechanisms can be recognized as providing certain micro-foundations for ITG as a dynamic capability competence. These mechanisms play an important role in the success of ITG within the organization (Peterson, 2004) and paramount for attaining and sustaining alignment between IT and business needs even when the appropriate structures and processes are in place (De Haes \& Van Grembergen, 2008). These mechanisms facilitate communication, collaboration, and the active participation of stakeholders, and develop a shared understanding of the IT function's role within the organization (i.e. social dimension of strategic alignment) (Van Grembergen et al., 2004; Preston \& Karahanna, 2009). At the same time, strategic alignment is seen to be positively associated with IT management sophistication (Karim et al., 2000). Given this, we posit that:

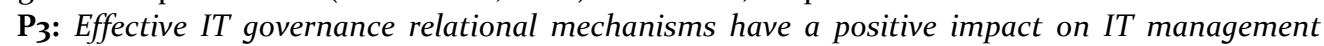
sophistication.

\subsection{IT Management Sophistication and IT Strategic Alignment}

Following past research on dynamic capabilities perspective (Pavlou \& El Sawy, 2006; Wang \& Ahmed, 2007), we posit, as detailed in previous section, IT management capabilities development and evolution (i.e. IT management sophistication) as an outcome of ITG. The path of building IT management capabilities is not universal across organizations and therefore IT management sophistication is different across organizations (Gupta, Karimi, \& Somers, 1997; Karimi et al., 2000; Karimi, Somers, \& Gupta, 2001; Kim, Shin, Kim, \& Lee, 2011). In fact, the level of IT management sophistication relates to the role of IT in the organization and its capacity to respond to business strategy (Gupta et al., 1997). A high degree of IT management sophistication suggests that the IT function has evolved from the basic role of supporting data-processing operations to a strategic partner role for the organization (Gupta et al., 1997; Karimi et al., 2000). Hence, IT management capabilities development and evolution (i.e. IT management sophistication) as an outcome of ITG is often steered by organization strategy. In line with this idea, Gupta et al. (1997) found that organization's competitive strategy has an impact on IT management sophistication. In addition, Karimi et al. (2000) posit effective IT management is often reflected in a conscious coordination of the relationship between business strategy and IT resources. As such, we propose that:

P4: IT management sophistication is positively associated with IT strategic alignment.

\subsection{IT Strategic Alignment and Organizational Performance}

The ultimate objective of ITG is to accomplish better IT strategic alignment and maximize the value of IT for the organization (De Haes \& Van Grembergen, 2008; IT-Governance Institute, 2003). Several studies have demonstrated strategic alignment to improve organizational performance (Chan, Sabherwal, \& Thatcher, 2006; Khaiata \& Zualkernan, 2009; Tallon, Kraemer, \& Gurbaxani, 2000). For example, Chan et al. (1997) found that companies that possess a high level of strategic alignment perform better than others do with respect to market growth, innovation and company reputation aspects. Moreover, companies that achieve strategic alignment of IT tend to attain greater competitive advantage, visibility, efficiency, and profitability (Luftman \& Brier, 1999). Other studies have shown that superior IT strategic alignment is positively related to organizational performance by promoting 
organizational learning and growth (Liang, Chiu, Wu, \& Straub, 2011). Karimi et al. (2001) also found that firms that strategically use their information technology tend to have more sophisticated IT management capabilities, resulting in greater competitive advantage, improved customer service, and better organizational performance. Given these research findings, we offer the following proposition:

$\mathbf{P}_{5}$ : IT strategic alignment is positively associated with organizational performance.

It is worth noting that our conceptual framework as presented in Figure 1 carries out three principal ideas:

(1) This model suggests that the effectiveness of ITG mechanisms contribute to the development of a dynamic ITG competence. ITG as a dynamic capability competence has an impact on the development of IT management capabilities and their evolution (i.e. IT management sophistication).

(2) At the same time, the path of building IT management capabilities is not universal across organizations, and therefore the outcome of IT management capability development is different across organizations. Organizations tend to develop IT management capabilities as directed by business strategy. Hence, this framework proposes that IT management capability development is an outcome of ITG dynamic competence, as steered by business strategy leading consequently to a certain level of strategic alignment.

(3) Moreover, ITG as a dynamic capability competence is more likely to lead to better organizational performance when IT management capabilities are developed in line with business strategy.

\section{Contributions, Limitations, and Future Research}

In this article, we proposed a conceptual framework to provide a more comprehensive understanding of the influence of ITG on organizational performance. In this section, we review the contributions, limitations, and future research directions borne from this research.

\subsection{Theoretical contribution}

As depicted from the literature review, there has been very little research on the link between ITG and organizational performance. Thus, this paper contributes to filling this research gap by providing a comprehensive conceptual framework that proposes an explanation of ITG organizational performance relationship. In addition, this research uses dynamic capabilities perspective as a theoretical basis to explain ITG impact on organizational performance. Through five research propositions, we explain that ITG leads to organizational performance, but the relationship is an indirect one mediated by IT management sophistication and strategic alignment.

\subsection{Managerial contribution}

This research in addition to its theoretical contributions also has some managerial implications as well. Inspired from our theoretical model, we argue that business and IT managers must cooperate to implement ITG mechanisms that will enable effective IT management. Moreover, our conceptual framework strengthens the idea of ITG as continuous process that should be monitored and evaluated on a regular basis so that its IT-related business value expectations could be realized and sustained over time.

\subsection{Limits and future research}

The conceptual framework propositions require further validation in future research, as we cannot say with certainty that each proposition is valid beyond the findings from past research that provide their collective basis. To address this limitation, it would be useful for future research to identify specific 
ITG mechanisms that can be recognized as providing certain micro- foundations for ITG dynamic competence. Moreover, to validate the propositions that comprise the conceptual framework, a longitudinal qualitative case-study research could be performed to estimate the effect of ITG as a dynamic capability competence on organizational performance over time. Semi-structured interviews with IT directors, business managers, and auditors of information systems can provide significant insight regarding the nature of the relationships we have proposed. In addition, we suggest the development of a multidimensional construct of ITG dynamic competence that could be validated through a quantitative research study and further examined in a nomological network to provide a better understanding of under what circumstances (e.g. contextual factors) ITG impacts on organizational performance.

\section{Conclusion}

In this article, we proposed a conceptual framework to explain the influence of ITG on organizational performance using dynamic capabilities perspective as a theoretical background. We argue that the relationship between ITG and organizational performance is more complex than a simple direct effect. Thus, we posit IT management sophistication and strategic alignment as mediators of this relationship. The proposed conceptual framework suggests that effective ITG mechanisms contribute to the development of a dynamic ITG competence, which in turn has an impact on the development of IT management capabilities and their evolution (i.e. IT management sophistication). Moreover, ITG is more likely to lead to better organizational performance when IT management capabilities are developed in line with business strategy suggesting the valuable effect of strategic alignment on organizational performance.

\section{References}

Agarwal, R., \& Sambamurthy, V. (2002). Principles and models for organizing the IT function. MIS Quarterly, 1(1), 1. Ali, S., \& Green, P. (2005). Determinants of effective information technology governance: A study of IT intensity. Paper presented at the International IT Governance Conference, Auckland, New Zealand.

Ali, S., \& Green, P. (2007). IT governance mechanisms in public sector organisations: An Australian context. J. Glob. Inf. Manag., 15(4), 41-63.

Ali, S., \& Green, P. (2012). Effective information technology (IT) governance mechanisms: An IT outsourcing perspective. Inf. Syst. Front., 14(2), 179-193.

Ambrosini, V., Bowman, C., \& Collier, N. (2009). Dynamic capabilities: an exploration of how firms renew their resource base. British journal of management, 20 (Special), 9-24.

Baker, J., Jones, D., Cao, Q., \& Song, J. (2011). Conceptualizing the dynamic strategic alignment competency. Journal of the Association for Information Systems, $12(4), 2$.

Barbosa, S. C. B., Rodello, I. A., \& Pádua, S. I. D. D. (2014). Performance measurement of information technology governance in brazilian financial institutions. JISTEM-Journal of Information Systems and Technology Management, 11(2), 397-414.

Beimborn, D., Schlosser, F., Weitzel, T. (2009, 2009). Proposing a theoretical model for IT governance and IT business alignment. Paper presented at the The Hawaii International Conference on System Sciences, Hawaii.

Bhattacharjya, J., \& Chang, V. (2007). Evolving IT governance practices for aligning IT with business - A case study in an Australian institution of higher education. J. Inf. Sci. and Technol., 4(1), 24.

Boritz, E., \& Lim, J.-H. (2007, 2007). Impact of top management's IT knowledge and IT governance mechanisms on financial performance. Paper presented at the International Conference on Information Systems (ICIS), Montreal.

Bradley R. V., \& Pratt, R. M. E. (2011). Exploring the relationships among corporate entrepreneurship, IT governance, and risk management. Paper presented at the the Hawaii International Conference on System Sciences, Hawaii.

Bradley, R. V., Byrd, T. A., Pridmore, J. L., Thrasher, E., Pratt, R. M., \& Mbarika, V. W. (2012). An empirical examination of antecedents and consequences of IT governance in US hospitals. J. Inf. Technol., 27(2), 156-177.

Brown, A. E., \& Grant, G. G. (2005). Framing the frameworks: A review of IT governance research. Commun. AIS, 15, 696-712. 
Brown, C. V. (1999). Horizontal mechanisms under differing IS organization contexts. MIS Quarterly, 23 (3), $421-454$.

Brown, C. V., \& Magill, S. L. (1994). Alignment of the IS functions with the enterprise: Toward a model of antecedents. MIS Q., 18(4), 371-403.

Brown, C. V., \& Ross, J. W. (2003). Designing a process-based IT organization. In C. V. Brown, \& H. Topi (Eds.), IS management handbook. (8 ${ }^{\text {th }}$ ed.). (pp. 125-133). Boca Raton, FL: CRC Press.

Brown, C. V. (1997). Examining the emergence of hybrid IS governance solutions: Evidence from a single case site. Information Systems Research, 8(1), 69.

Callahan, J., \& Keyes, D. (2004). The evolution of IT governance at NB power. In Van Grembergen (Ed.), Strategies for information technology governance (pp. 343-356). Hershey, PA: Idea Group Publishing.

Chang, J. C.-J., \& King, W. R. (2003). Measuring the performance of information systems: a functional scorecard. Journal of Management Information Systems, 22(1), 85-115.

Chan, Y. E., Huff, S. L., Barclay, D. W., \& Copeland, D. G. (1997). Business strategic orientation, information systems strategic orientation, and strategic alignment. Inf. Syst. Res., 8(2), 125-150.

Chan, Y. E., Sabherwal, R., \& Thatcher, J. B. (2006). Antecedents and outcomes of strategic IS alignment: An empirical investigation. IEEE Trans. Eng. Manag., 53(1), 27-47.

Chen, R. S., Sun, C. M., Helms, M. M., \& Jih, W. J. K. (2008). Aligning information technology and business strategy with a dynamic capabilities perspective: A longitudinal study of a Taiwanese Semiconductor Company. International Journal of Information Management, 28(5), 366-378.

Cobo, A., Vanti, A. A., \& Rocha, R. (2014). A fuzzy multicriteria approach for it governance evaluation. JISTEMJournal of Information Systems and Technology Management, 11(2), 257-276.

Coleman, T., Chatfield, A. T. (2011). Promises and successful practice in IT governance: A survey of Australian senior IT managers. Paper presented at the Pacific Asia Conference on Information Systems (PACIS), Australia.

Collis, D. J. (1994). Research note: how valuable are organizational capabilities? Strategic Management Journal, 15( $\left.\mathrm{S}_{1}\right), 143-152$.

Crowston, K., \& Osborn, C. (1998). A coordination theory approach to process description and redesign (pp. 59): Massachusetts Institute of Technology Sloan School of Management

Center for Coordination Science.

Dahlberg, T., \& Kivijärvi, H. (2006). An integrated framework for IT governance and the development and validation of an assessment instrument. Paper presented at the Hawaii International Conference on System Sciences (HICSS), Hawaii.

Dahlberg, T., Lahdelma, P. (2007). IT governance maturity and IT outsourcing degree: An exploratory study. Paper presented at the The Hawaii International Conference on System Sciences, Hawaii.

De Haes, S., Gemke, D., Thorp, J., \& Van Grembergen, W. (2011). KLM'S enterprise governance of IT journey: From managing IT costs to managing business value. MIS Q. Exec., 10(3), 109-120.

De Haes, S., \& Van Grembergen, W. (2009). Exploring the relationship between IT governance practices and business/IT alignment through extreme case analysis in Belgian mid-to-large size financial enterprises. J. of Enterp. Inf. Manag., 22(5), 615-637.

De Haes, S., \& Van Grembergen, W. (2009). An exploratory study into IT governance implementations and its impact on business/IT alignment. Inf. Syst. Manag., 26(2), 123-137.

De Haes, S., \& Van Grembergen, W. (2008). An Exploratory Study into the Design of an IT Governance Minimum Baseline through Delphi Research. [Article]. Communications of AIS, 2008(22), 443-458.

Decoene, V., \& Bruggeman, W. (2006). Strategic alignment and middle-level managers' motivation in a balanced scorecard setting. International Journal of Operations \& Production Management, 26(4), 429-448.

De Souza Bermejo, P. H., Tonelli, A. O., \& Zambalde, A. L. (2014). Developing IT Governance in Brazilian Public Organizations. International Business Research, 7(3), p1o1.

Duhan, S. (2007). A capabilities based toolkit for strategic information systems planning in SMEs. Int. J. Inf. Manag., $27(5), 352-367$.

Ein-Dor, P., \& Segev, E. (1982). Organizational context and MIS structure: Some empirical evidence. MIS Q., 6(3), 55-68.

Eisenhardt, K. M., \& Martin, J. A. (200o). Dynamic capabilities: What are they? Strategic Management Journal, 21(10/11), 1105-1121.

Ferguson, C., Green, P., Vaswani, R., \& Wu, G. (2013). Determinants of effective information technology governance. Int. J. Audit., 17(1), 75-99.

Fink, K., Ploder, C. (2008). Decision support framework for the implementation of IT-governance. Paper presented at the The Hawaii International Conference on System Sciences, Hawaii.

Galbraith, J. R. (1973). Designing Complex Organizations: Addison-Wesley. 
Goosen, R., \& Rudman, R. (2013). The development of an integrated framework in order to address King III's IT governance principles at a strategic level. South African Journal of Business Management, 44(4), 91-103.

Grüttner, V., Pinheiro, F., \& Itaborahy, A. (2010). IT governance implementation - Case of a Brazilian bank. Paper presented at the Americas Conference on Information Systems (AMCIS), Peru.

Gupta, Y. P., Karimi, J., \& Somers, T. M. (1997). Alignment of a firm's competitive strategy and information technology management sophistication: The missing link. IEEE Transactions on Engineering Management, 44(4), 399-413.

Heindrickson, G., \& Carlos Jr, D. (2014). Information technology governance in public organizations: how perceived effectiveness relates to three classical mechanisms. JISTEM-Journal of Information Systems and Technology Management, 11(2), 297-326.

Huang, L. K. (2009). The contingent role of innovation between IT management sophistication and strategic alignment. Journal of Global Information Management, 17(2), 60-92.

$\mathrm{Hu}, \mathrm{Q}$., \& Huang, C. D. (2006). Using the Balanced Scorecard to Achieve Sustained IT-Business Alignment: A Case Study. Communications of the Association for Information Systems, 17, 1-1.

IT Governance Institute. (2003). Board Briefing on IT Governance, 2 nd Edition (pp. 65): IT Governance Institute.

IT Governance Institute. (2005). Cobit 4.0 (pp. 209).

IT Governance Institute. (20o8). Unlocking Value: An Executive Primer on the Critical Role of IT Governance (pp. 29): Information Systems Audit and Control Association.

Jewer, J., \& McKay, K. N. (2012). Antecedents and consequences of board IT governance: Institutional and strategic choice perspectives. J. Assoc. Inf. Syst., 13(7), 581-617.

Juiz, C., \& Toomey, M. (2015). To govern IT, or not to govern IT?.Communications of the ACM, 58(2), 58-64.

Karimi, J., Gupta, Y. P., \& Somers, T. M. (1996). Impact of competitive strategy and information technology maturity on firms' strategic response to globalization. J. Manag. Inf. Syst., 12(4), 55-88.

Karimi, J., Bhattacherjee, A., Gupta, Y. P., \& Somers, T. M. (2000). The effects of MIS steering committees on information technology management sophistication. Journal of Management Information Systems, 17(2), 207230.

Karimi, J., Somers, T. M., \& Gupta, Y. P. (2001). Impact of information technology management practices on customer service. Journal of Management Information Systems, 17(4), 125-158.

Khaiata, M., \& Zualkernan, I. A. (2009). A simple instrument to measure IT-business alignment maturity. Inf. Syst. Manag., 26(2), 138-152.

Kim, G., Shin, B., Kim, K. K., \& Lee, H. G. (2011). IT Capabilities, Process-Oriented Dynamic Capabilities, and Firm Financial Performance*. Journal of the Association for Information Systems, 12(7), 487-517.

Kuruzovich, J., Bassellier, G., \& Sambamurthy, V. (2012). IT governance processes and IT alignment: Viewpoints from the Board of Directors. Paper presented at the The Hawaii International Conference on System Sciences (HICSS), Hawaii.

Dahlberg, T., \& Lahdelma, P. (2007). IT governance maturity and IT outsourcing degree: An exploratory study. In 4oth Annual Hawaii International Conference on System Sciences (HICSS'o7). IEEE.

Lawrence, P. R., \& Lorsch, J. W. (1967). Adapter les structures de l'entreprise: Intégration ou différenciation. Éditions d'Organisation.

Lazic, M., Groth, M., Schillinger, C., \& Heinzl, A. (2011). The impact of IT governance on business performance. Paper presented at the AMCIS, Michigan.

Lee, C.-H., Lee, J.-H., Park, J.-S., \& Jeong, K.-Y. (2008). A study of the causal relationship between IT governance inhibitors and its success in Korea enterprises. Paper presented at the Hawaii International Conference on System Sciences, Hawaii.

Lee, J.-H., Juhn, S-H, Hwang, K-T (2009). New development of advanced ITG framework. Paper presented at the The Hawaii International Conference on System Sciences, Hawaii.

Liang, T. P., Chiu, Y. C., Wu, S. P. J., \& Straub, D. (2011). The Impact of IT Governance on Organizational Performance. Paper presented at the Americas Conference on Information Systems - AMCIS.

Luftman, J., \& Brier, T. (1999). Achieving and sustaining business-IT alignment. Calif. Manag. Rev., 42(1), $109-122$.

Luftman, J., \& Zadeh, H. S. (2011). Key information technology and management issues 2010-11: an international study. J. Inf. Technol., 26(3), 193-204.

Lunardi, G. L., Maçada, A. C. G., Becker, J. L., \& Van Grembergen, W. (2017). Antecedents of IT governance effectiveness: An empirical examination in Brazilian firms. Journal of Information Systems, 31(1), 41-57.

Makadok, R. (2001). Toward a synthesis of the resource-based and dynamic-capability views of rent creation. Strateg. Manag. J., 22(5), 387-401.

Mintzberg, H. (1979). Structure et dynamique des organisations. 
Olson, M. H., \& Chervany, N. L. (1980). The relationship between organizational characteristics and the structure of the information services function. MIS Q., 4(2), 57-68.

Pavlou, P. A., \& El Sawy, O. A. (2006). From IT leveraging competence to competitive advantage in turbulent environments: The case of new product development. Information Systems Research, 17(3), 198-227.

Pavlou, P. A., \& El Sawy, O. A. (2011). Understanding the Elusive Black Box of Dynamic Capabilities. Decision Sciences, 42(1), 239.

Pelletier, C. (2012). Le processus de l'alignementstratégique des ti: reconceptualisation par les capacitésdynamiques. Paper presented at the ASAC, Newfoundland.

Peterson, R. R. (2000). Emerging capabilities of information technology governance: Exploring stakeholder perspectives in financial services. Paper presented at the European Conference on Information Systems (ECIS), Austria.

Peterson, R. R. (2004). Integration Strategies and Tactics for Information Technology Governance. In I. G. Inc. (Ed.), Strategies for Information Technology Governance (pp. 44).

Peterson, R. (2005). Trends in information technology governance. Encyclopedia of information science and technology. ( $2^{\text {nd }}$ ed.), pp. 5266, USA: information resources management association.

Prasad, A., Green, P., \& Heales, J. (2013). Beyond normal competencies: understanding organisation designs to develop and sustain IT-related capabilities. Australasian Journal of Information Systems, 18(1).

Prasad, A., Heales, J., \& Green, P. (2010). A capabilities-based approach to obtaining a deeper understanding of information technology governance effectiveness: Evidence from IT steering committees. International Journal of Accounting Information Systems Management, 11, 19.

Preston, D. S., \& Karahanna, E. (2009). Antecedents of IS strategic alignment: a nomological network. Information Systems Research, 20(2), 159-179.

Priem, R. L., Butler, J. E. (2001). Is the resource-based "view" a useful perspective for strategic management research? Acad. Manag. Rev., 26(1), 22-40.

Ryan, S. D., \& Harrison, D. A. (200o). Considering social subsystem costs and benefits in information technology investment decisions: A view from the field on anticipated payoffs. J. Manag. Inf. Syst., 16(4), 11-40

Ryan, S. D., Harrison, D. A., \& Schkade, L. L. (2002). Information-technology investment decisions: when do costs and benefits in the social subsystem matter?. Journal of Management Information Systems, 19(2), 85-127.

Sambamurthy, V., \& Zmud, R. W. (1999). Arrangements for information technology governance: A theory of multiple contingencies. MIS Q., 23(2), 261-290.

Schlosser, F., \& Wagner, H.-T. (2011). IT governance practices for improving strategic and operational business-IT alignment. Paper presented at the Pacific Asia Conference on Information Systems (PACIS), Australia.

Schobel, K., \& Denford, J. S. (2012). The chief information officer and chief financial officer dyad in the public sector: How an effective relationship impacts individual effectiveness and strategic alignment. Journal of Information Systems, 27(1), 261-281.

Simonsson, M., Johnson, P., \& Ekstedt, M. (2010). The effect of IT governance maturity on IT governance performance. Inf. Syst. Manag., 27(1), 10-24.

Subsermsri, P., Jairak, K., \& Praneetpolgrang, P. (2015). Information technology governance practices based on sufficiency economy philosophy in the Thai university sector. Information Technology E People, 28(1), 195223.

Tallon, P. P., Kraemer, K. L., \& Gurbaxani, V. (200o). Executives' perceptions of the business value of information technology: A process-oriented approach. J. Manag. Inf. Syst., 16(4), 145-173.

Tavakolian, H. (1989). Linking the information technology structure with organizational competitive strategy: A survey. MIS Q., 13(3), 309-317.

Teece, D. J. (2007). Explicating dynamic capabilities: the nature and microfoundations of (sustainable) enterprise performance. Strategic Management Journal, 28(13), 1319-1350.

Teece, D. J., Pisano, G., \& Shuen, A. (1997). Dynamic Capabilities and Strategic Management. Strategic Management Journal (1986-1998), 18(7), 509.

Thompson, J. D. (1967). Organizations in action: Social science bases of administrative theory. New York: McGrawHill.

Tugas, F. C. (2010). Assessing the level of information technology (IT) processes performance and capability maturity in the Philippine food, beverage, and tobacco (FTB) industry using the Cobit framework. Acad. Inf. Manag. Sci. J., 13(1), 45-68.

Turel, O., \& Bart, C. (2014). Board-level IT governance and organizational performance. European Journal of Information Systems, 23(2), 223-239.

Vaia, G., \& Carmel, E. (2013). Reshaping the IT governance in Octo Telematics to gain IT-business alignment. Journal of Information Technology Teaching Cases, 3(2), 88-95. 
Van Grembergen, W. (200o). The Balanced Scorecard and IT Governance ISACA Journal, 2.

Van Grembergen, W., Saull, R., \& De Haes, S. (2003). Linking the IT balanced scorecard to the business objectives at a major Canadian financial group. Journal of Information Technology Cases and Applications, 5(1), $23-45$.

Van Grembergen, W., De Haes, S., \& Guldentops, E. (2004). Structures, processes and relational mechanisms for IT governance. In W. van Grembergen (Ed.), Strategies for information technology governance (pp. 1-36). Hershey, PA: Idea Group, Inc.

Wang, C. L., \& Ahmed, P. K. (2007). Dynamic capabilities: A review and research agenda. International Journal of Management Reviews, 9(1), 31-51.

Weill, P., \& Ross, J. W. (2004). IT governance: How top performers manage IT decision rights for superior results: Harvard Business Press.

Williams, C. K., \& Karahanna, E. (2013). Causal explanation in the coordinating process: A critical realist case study of federated IT governance structures. MIS Quarterly, 37(3), 933-964. 